\title{
Absorption capacity, kinetics and mechanical behaviour in dry and wet states of hydrophobic DEDMS/TEOS-based silica aerogels
}

Víctor Morales-Florez ${ }^{1,2}$, Manuel Piñero ${ }^{3, *}$, Verónica Braza ${ }^{4}$, María del Mar Mesa ${ }^{5}$, Luis Esquivias ${ }^{1,2}$, Nicolás de la Rosa-Fox ${ }^{6}$

1 Dpto. Física de la Materia Condensada, Facultad de Física, Universidad de Sevilla Av. Reina Mercedes s/n 41012 Sevilla (Spain)

2 Instituto de Ciencia de Materiales de Sevilla CSIC-US, Av. Américo Vespucio 4941012 Sevilla (Spain)

3 Dpto. Física Aplicada, Escuela Superior de Ingeniería, Universidad de Cádiz 11519 Puerto Real, Cádiz (Spain)

4 Dpto. Ciencias de los Materiales e Ingeniería Metalúrgica y Química Inorganica, Facultad de Ciencias Universidad de Cádiz 11510 Puerto Real, Cádiz (Spain)

5 Dpto. Ing. Química y Tecnologías del Medio Ambiente Facultad de Ciencias Universidad de Cádiz. 11510 Puerto Real, Cádiz (Spain)

6 Dpto. Física de la Materia Condensada, Facultad de Ciencias Universidad de Cádiz 11510 Puerto Real, Cádiz (Spain)

Corresponding author: Dr. Manuel Piñero de los Ríos.

Email: manolo.piniero@uca.es · Tel.: +34956016077 · Fax: +34956016079

\section{Keywords}

Hybrid materials · DEDMS-TEOS · Nanostructure $\cdot$ Absorption $\cdot$ Swelling $\cdot$ Uniaxial compression

\section{Graphical abstract}
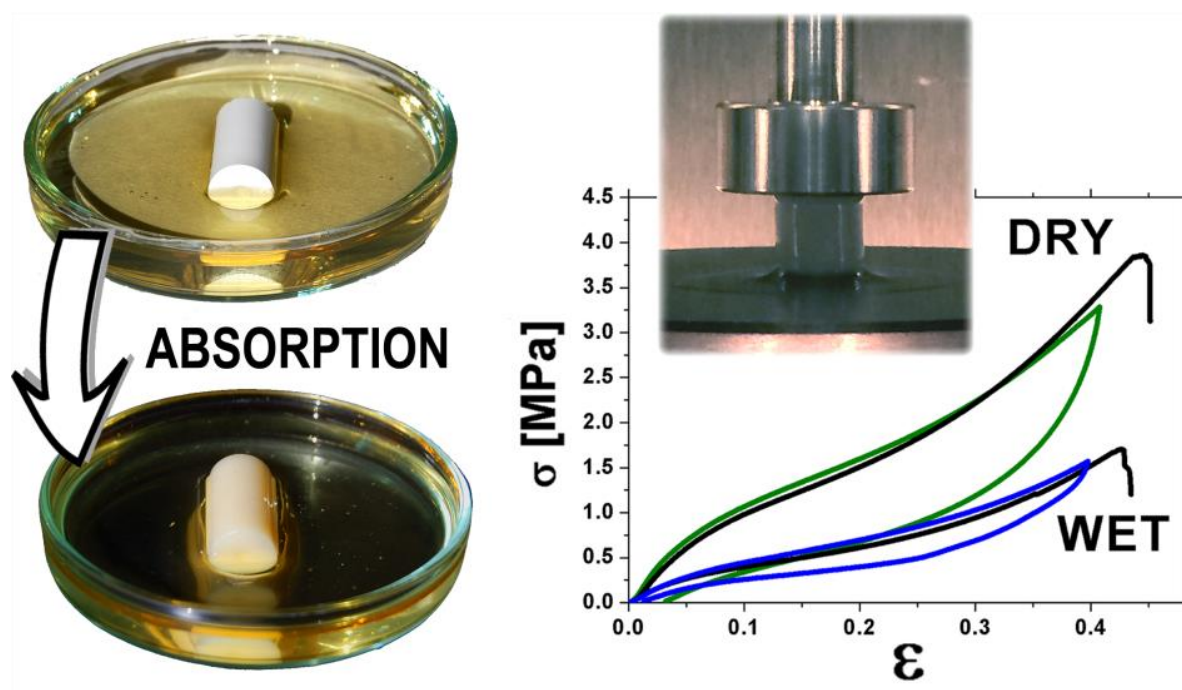


\begin{abstract}
This work is a new approach to the study of the structural, mechanical and absorption properties of hybrid organic/inorganic silica-based aerogels. Diethoxydimethylsilane and tetraethoxysilane have been used as precursors. Changes in properties such as specific surface area, porous volume, pore radius and surface texture and chemistry were researched as a function of the relative organic content. In addition, the absorption properties were tested for different organic liquids. The discrepancy in the absorption mechanisms and the kinetics of pure inorganic and hybrid samples were discussed. It was confirmed that swelling occurs in samples with high organic content, which, in turn, governs the absorption process. Finally, the mechanical behaviour was studied by uniaxial compression. A significant rise of the rupture strain up to 0.45 and a 10 -fold decrease in the Young's modulus to $7.8 \mathrm{MPa}$ were measured in the dry samples by increasing the organic content. The mechanical response of the samples after saturation by the absorption of two reference oily liquids, namely, common motor oil and liquid PDMS, was also compared with the behaviour of dry samples. The presence of liquid within the sample reduced the value of the mechanical parameters in almost all cases. Moreover, the inclusion of organic chains also made the wet aerogels highly deformable. In summary, our results suggest that tuning the organic ratio of the hybrid aerogels allows the control of not only the structural and mechanical properties but also the absorption properties.
\end{abstract}




\section{Introduction}

The absorption of liquids by porous materials has been widely researched because it is a basic transport phenomenon that is of interest in very different areas such as physics of fluids, soil science, biomaterials, food industry and engineering [1-3]. The absorption process can be a spontaneous process driven by capillary forces, involving the diffusion of a liquid through the porous structure of the sorbent. The sorbents are insoluble materials that can capture and retain liquids confined throughout their structure under certain conditions. Typically, sorbents formed by organic polymers may undergo swelling when the inflowing liquid interacts with the organic network [4]. Thus, the absorption of liquids by porous media forms a vast field, in which the affinity between the sorbent and liquid, the porous structure of the sorbent, and the evolution of the structure upon absorption are key features.

Absorption-related problems are present in a variety of technological challenges. For example, the understanding of mechano-sensing and actuation in micron-size and nanostructured systems of plants and arthropods based on water absorption and swelling may provide interesting ideas for the engineering of new micromechanical devices [5, 6]. Thereby, biologists and materials scientists have been prompted to cooperative research due to the ever-growing need for new types of biomaterials with specific and well-defined interactions with the possible biological host systems. Other examples include environmental applications of porous materials, such as hybrid silica-based aerogels among others. This kind of samples have already been proposed as sorbents for the clean-up of oils or toxic waste spills after accidental release, demonstrating good performance, achieving amounts of absorbed liquid up to several times that of the aerogel by volume $[7,8]$.

One of the advantages of working with organic/inorganic hybrid aerogels for specific applications, such as absorption of liquids, is their simple and versatile method of synthesis and their easy-to-tune properties. The sol-gel method for aerogel synthesis enables the formation of cross-linked hybrid organic-inorganic networks, facilitating the introduction of certain chemical groups to control surface wettability and selective sorption, leading to pre-determined surface morphologies or physico-chemical functionalities $[9,10]$. In addition, the mechanical properties can also be gradually modified, from the brittleness and rigidity typical of pure silica aerogels, to the elastomeric behaviour of the organic polymers [11-13]. Therefore, the properties of the 
hybrid materials can be tailored by properly selecting the organic and inorganic constitutive phases and controlling their relative content, in order to meet specific requirements of particular technological applications.

One of the most studied hybrid aerogels is made of silica and polydimethylsiloxane (PDMS) [14, 15]. The PDMS consists of repeated units of dimethylsiloxane (DMS), $\left[\left(\mathrm{CH}_{3}\right)_{2} \mathrm{SiO}\right]_{\mathrm{n}}$, forming flexible linear chains, and presents unique properties, such as elasticity, thermal stability, biocompatibility, optical transparency, chemical inertness and electrical insulation. Besides, thanks to its hydrophobicity and oleophilicity, PDMSbased materials have already been used to selectively separate oils from water with high absorption capacity, fast absorption, and excellent reusability [16, 17]. Typical PDMSbased materials are largely compliant, with elastic moduli far below $0.1 \mathrm{MPa}$ and extraordinarily large elongations [18]. Hence, the combination of this organic phase with the silica porous matrix can lead to hybrid materials with good thermal and absorption capacities, and with tuneable mechanical properties, characteristics which cannot be managed by either organic polymers or glasses separately [19, 20].

In the present paper we report the structural properties of new hybrid silica-based aerogels synthesized from TEOS and different contents of diethoxydimethylsilane (DEDMS). The samples were also tested as absorbents for a variety of liquids: hexane, heptane, octane, tetrahydrofurane, toluene, benzene, ethanol, common motor oil and liquid PDMS. Moreover, the mechanical behaviour of the samples has been also studied, not only in the dry state (before absorption), but also after the absorption saturation of two liquids: motor oil and PDMS. To our knowledge, the study of the mechanical properties by uniaxial compression of hybrid porous materials filled with organic liquids after absorption experiments or swelling is a subject scarcely investigated and this work wants to contribute to this combined research subject, introducing the first results based on DEDMS-TEOS aerogels.

\section{Experimental}

\subsection{Preparation of sols and aerogels}

For the synthesis of the samples, we have used the methodology of Babonneau et al., [21, 22], which consisted in the hybridization of a silica network with short PDMS 
chains formed in situ by copolymerization of tetraethoxysilane (TEOS) and monomeric diethoxydimethylsilane (DEDMS). Sols were prepared by a one-step sol-gel process by mixing TEOS (Merck, Germany; purity $\geq 99 \%$ ) and DEDMS (ABCR, Germany; $97 \%$ ) in absolute ethanol (MARCA?? $99.5 \%$ ), with the DEDMS/TEOS molar ratio ranging from 0 to 1.25 , corresponding to 0 to $50 \mathrm{wt}$. $\%$ of the organic phase regarding the silica content of the sample. The mixtures were hydrolyzed in acidic water at $\mathrm{pH}=1\left(\mathrm{HNO}_{3}\right.$, Panreac, Spain; $60 \%$ ) under the catalyst effects of ultrasounds, by supplying $0.6 \mathrm{~kJ} \mathrm{~cm}^{-3}$ of sonic power. All chemical reactions were carried out in a flask immersed in a cooling bath at $0{ }^{\circ} \mathrm{C}$. After the hydrolysis reaction, the resulting sol was poured into cylindrical containers which were sealed and stored in a stove at $50{ }^{\circ} \mathrm{C}$ until gelation (around $24 \mathrm{~h}$ ). Then the gels were aged soaked in ethanol for 7 days at $25^{\circ} \mathrm{C}$ in closed containers. Dry samples were then obtained by supercritical drying with ethanol in an autoclave of 500 $\mathrm{mL}$ capacity. During this process, temperature was raised at a rate of $1^{\circ} \mathrm{C} / \mathrm{min}$ to prevent crossing the vapour-liquid equilibrium line, until $\mathrm{T}=260^{\circ} \mathrm{C}$, which resulted in an increase in pressure to $8 \mathrm{MPa}$. These conditions were maintained for $30 \mathrm{~min}$, and then the ethanol was isothermally evacuated. Cylinder-shaped hybrid monolithic aerogels were obtained with dimensions: $16.50 \mathrm{~mm}$ in height and $8.50 \mathrm{~mm}$ in diameter. The aerogels were labelled as $T D X$, ' $X$ ' being the DEDMS/TEOS molar ratio.

\subsection{Characterization of hybrid DEDMS/TEOS aerogels}

The density was easily obtained by measuring the mass and the size of the cylindrical samples with a calliper and a microbalance (precision $\pm 0.1 \mathrm{mg}$ ). The nanostructural changes occurring in the silica aerogel due to its hybridization with DEDMS were investigated by means of nitrogen physisorption experiments (Micromeritics ASAP2010, working at $77 \mathrm{~K}$ and equipped with pressure transducer resolution of $10^{-4} \mathrm{~mm} \mathrm{Hg}$ ). Specific surface area, specific pore volume and pore diameter were determined, considering standard models for the analysis (BET and BJH, respectively). Prior to these experiments, samples were milled in an agate mortar and degasified at $150{ }^{\circ} \mathrm{C}$ for $2 \mathrm{~h}$. The study of the microstructural surface morphology was performed by scanning electron microscopy (SEM) with a thermoionic filament emission (FEI Quanta; resolution: $3.5 \mathrm{~nm}$ ) using the low-vacuum capability in the pressure range $10-130 \mathrm{~Pa}$, which enables analysis of wet specimens without previous preparation. The level of hydrophobicity (or oleophilicity) was studied by measuring 
the contact angle $\theta$ of a drop deposited on the flat surface of the monolithic aerogels with the ImageJ software. The values were averaged from at least 5 images. Surface chemical structure was studied by Fourier transform infrared spectroscopy (FTIR). All the infrared spectra were collected at room temperature on a Fourier transform spectrometer (Bruker VERTEX 80) with a resolution of $4 \mathrm{~cm}^{-1}$ and 100 scans in the region $4000-400 \mathrm{~cm}^{-1}$. The sample was ground and mixed with $\mathrm{KBr}$ and pressed into a self-supporting wafer. The wafer was put on a sample holder for spectrum collection.

\subsection{Absorption of liquids}

Cylinder specimens of hybrid aerogels were used for batch absorption experiments of different liquids at room temperature. The absorption capacities of the samples were evaluated by putting them into contact with a common type of motor oil (71 cst viscosity at $40{ }^{\circ} \mathrm{C}$ and $0.875 \mathrm{~g} \mathrm{~cm}^{-3}$ density at $15^{\circ} \mathrm{C}$ ), and with silanol-terminated PDMS fluid of low viscosity $\left(450 \mathrm{~g} \mathrm{~mol}^{-1}\right.$ in average molar mass, $0.965 \mathrm{~g} \mathrm{~cm}^{-3}$ density, and $20-$ 32 cst viscosity at $15^{\circ} \mathrm{C}$ ), as reference oily fluids [23]. The experiments were performed twice to check consistency. Also, several organic liquids with different functionality and molecular weight were tested for absorption: hexane, heptane, octane, tetrahydrofurane, toluene, benzene and ethanol. The absorption capacity was defined as the absorbed mass per unit weight of the original dry aerogel. It can be obtained in grams of the absorbed fluid per grams of dry sample using Eq. (1).

$$
\text { Absorption capacity: } \quad M^{*}=\frac{M(\infty)-M(0)}{M(0)} \quad \text { [Eq. 1] }
$$

where $M(0)$ and $M(\infty)$ are the weights of samples before absorption and after saturation by the absorption, respectively. Before each measurement was made, the excess surface liquid was wiped out from the specimens and the weights were recorded, then immediately returning the sample to the bath. This process was repeated until no weight change was observed for several hours. In the case of PDMS, the time-dependence of the absorbed mass was monitored for kinetic studies.

\subsection{Mechanical tests}

Mechanical properties were also characterized by uniaxial compression (Shimadzu AG-I Autograph $5 \mathrm{kN}$, within a $\pm 1 \%$ of indicated test force at 1/250 load cell rating) 
using a sample deformation rate of $0.5 \mathrm{~mm} \mathrm{~min}^{-1}$. Uniaxial compression was performed on dry samples and in wet samples. For measurements with wet samples, the fluidsaturated aerogels were taken out of the liquid container and subjected to unconfined uniaxial compression. In this way, the liquid recovery ability could also be estimated. Stress-at-failure was estimated from the maximum supported stress prior to sample failure. The elastic modulus was estimated by averaging the slope of the stress-strain loading curve.

\section{RESULTS}

\subsection{Basic characterization}

The hybrid aerogels with DEDMS/TEOS molar ratio varying from 0 to 1.25 (0 to 50 wt. \%), were obtained as monolithic cylinders. The sample TD0 was a classical pure acid-catalyzed silica aerogel, transparent, brittle and fragile upon handling. On the other hand, the TD1.25 specimen was opaque, and presents good consistency upon handling. The well-defined geometry allowed the estimation of the density of the samples for different DEDMS contents. In Table 1, the variation of the density can be seen, from the $\rho=0.27 \mathrm{~g} \mathrm{~cm}^{-3}$ pure inorganic sample (TD0) to the $\rho=0.38 \mathrm{~g} \mathrm{~cm}^{-3}$ of the TD1.25 sample.

\begin{tabular}{cccccc} 
Sample & $\begin{array}{c}\boldsymbol{\rho}_{\mathbf{a}} \\
\left(\mathbf{\pm 0 . 0 4} \mathbf{g} \mathbf{~ c m}^{\mathbf{3}}\right)\end{array}$ & $\begin{array}{c}\mathbf{S}_{\mathbf{B E T}} \\
\left(\mathbf{m}^{\mathbf{2}} \mathbf{g}^{-\mathbf{1}}\right)\end{array}$ & $\begin{array}{c}\mathbf{V}_{\mathbf{p}} \\
\left(\mathbf{c m}^{\mathbf{3}} \mathbf{g}^{\mathbf{- 1}}\right)\end{array}$ & $\begin{array}{c}\text { Pore size } \\
(\mathbf{n m})\end{array}$ & $\begin{array}{c}\mathbf{S} / \mathbf{V} \\
\left(\mathbf{m}^{\mathbf{2}} \mathbf{~ c m}^{\mathbf{3}}\right)\end{array}$ \\
\hline TD0 & 0.27 & 900 & 3.306 & 12.1 & 272 \\
\hline TD0.38 & 0.39 & 751 & 2.698 & 11.8 & 278 \\
\hline TD0.50 & 0.44 & 910 & 1.059 & 4.37 & 859 \\
\hline TD0.75 & - & 810 & 0.498 & 2.75 & 1626 \\
\hline TD1.00 & 0.39 & 699 & 1.496 & 10.5 & 467 \\
\hline TD1.25 & 0.38 & 43 & 0.139 & 11.0 & 311 \\
\hline
\end{tabular}

Table 1 Bulk density and textural data from $\mathrm{N}_{2}$ physisorption for $T D X$ aerogels $(X=$ DEDMS/TEOS molar ratio). Specific surface $S_{\text {BET }}$ correlation coefficient in BET fitting was higher than 0.9995 in all cases. (-) No well-defined monolithic sample of the TD0.75 type was obtained so density could not be estimated.

These values are quite similar to those previously reported for similar types of samples $[7,11,14]$. And the non-uniform trend in the density reflects macroscopically the progressive incorporation of the organic phase in the porous matrix of the sample until the change of character. That is, for low organic content, DMS monomers or small 
PDMS chains are incorporated between the silica clusters. But above a certain critical value, the organic DMS constitutes the major building phase of the structure, changing qualitatively the character of the matrix to a denser, less porous organic structure where the silica clusters are embedded [11,22]. In this regard, it is known that the percolation of the organic phase is expected for a $40 \mathrm{wt}$. \% [24], that is, a 1.00 DEDMS/TEOS molar ratio. Therefore, for quantities of the DEDMS precursor above this value, the porous matrix is expected to be described as an organic phase where embedded clusters of silica can be found, instead of a silica porous matrix with embedded DMS chains.

The contact angles of water were averaged from 5 different tests. The obtained values were $\theta=123^{\circ} \pm 5^{\circ}$ and $\theta=139^{\circ} \pm 8^{\circ}$ on the TD0 and TD1.25 samples, respectively. The hydrophobicity of this kind of pure silica aerogel has been discussed previously in terms of the probable condensation of silanol groups during the hightemperature supercritical drying process in ethanol $\left(260{ }^{\circ} \mathrm{C}\right.$ for $\left.5 \mathrm{~h}\right)$, and the presence of non-reacted ethoxy radicals $[7,9,15,25]$. On the other hand, the surface coverage of the non-polar methyl groups of the DEDMS confers more hydrophobicity to the sample TD1.25. On the contrary, contact angles very close to $0^{\circ}$ for common motor oil on both the tested samples, TD0 and TD1.25, were obtained, confirming the good oleophilicity and, besides, the expected ability of these samples for oil recovery from wastewaters (see pictures of sample TD1.25 in Fig. SM1, Online Resource 1).

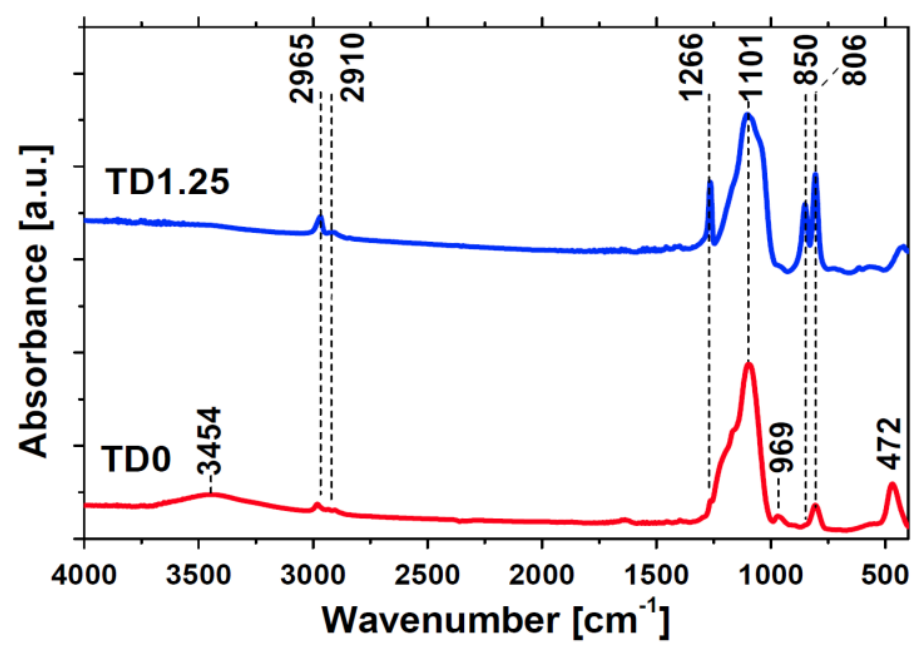

Fig. 1 Fourier-transformed infrared spectra from TD0 and TD1.25 aerogels

The FTIR spectra of the sample TD0 (Fig. 1) shows a broad absorption band centred around $3450 \mathrm{~cm}^{-1}$ and another short one at $969 \mathrm{~cm}^{-1}$, corresponding to H-bonded silanols and the surface silanols, respectively, and three additional bands centred at 1101 
$\mathrm{cm}^{-1}, 806 \mathrm{~cm}^{-1}$ and $472 \mathrm{~cm}^{-1}$ associated with the Si-O-Si antisymmetric and symmetric stretching vibration mode, and bending mode vibration of $\mathrm{Si}-\mathrm{O}-\mathrm{Si}$, respectively $[15,26$ 28]. Absorption bands corresponding to the traces of surface ethoxy radical, which conferred the hydrophobic character to this sample, were observed at the $\mathrm{C}-\mathrm{H}$ stretching frequencies at $2965 \mathrm{~cm}^{-1}$ and $2910 \mathrm{~cm}^{-1}$. On the contrary, the absence of silanol groups and presence of methyl radicals at the surface of the sample are evidenced in the spectra of TD1.25 by the disappearance of the broad band centred at $3454 \mathrm{~cm}^{-1}$ and the appearance of well-defined absorption peaks at $1266 \mathrm{~cm}^{-1}$ and $850 \mathrm{~cm}^{-1}$ [27]. These chemical changes of the surface are responsible for the increased hydrophobicity of sample TD1.25.

\subsubsection{Nano and microstructure}

The nanostructure of the samples was researched by nitrogen physisorption experiments. All the samples exhibited type IV isotherms with a hysteresis loop (Fig. SM2, top in Online Resource 1), which indicate interconnected mesoporous structures for which multilayer adsorption with capillary condensation took place. A shift from a type H1 hysteresis loop (TD0 aerogel) to a type H3 hysteresis loop (TD1.25 aerogel) was observed by the concurrence of a long tail of the desorption isotherm towards low relative pressures. $\mathrm{H} 1$ is characteristic of materials with uniform pores and narrow pore size distributions according to previous structural studies on silica aerogel [29]. Otherwise, H3 hysteresis does not exhibit any limiting adsorption at high relative pressure and corresponds to the existence of non-rigid aggregates with interconnected pores. The most relevant values of the structural parameters of the sample series are shown in Table 1. 


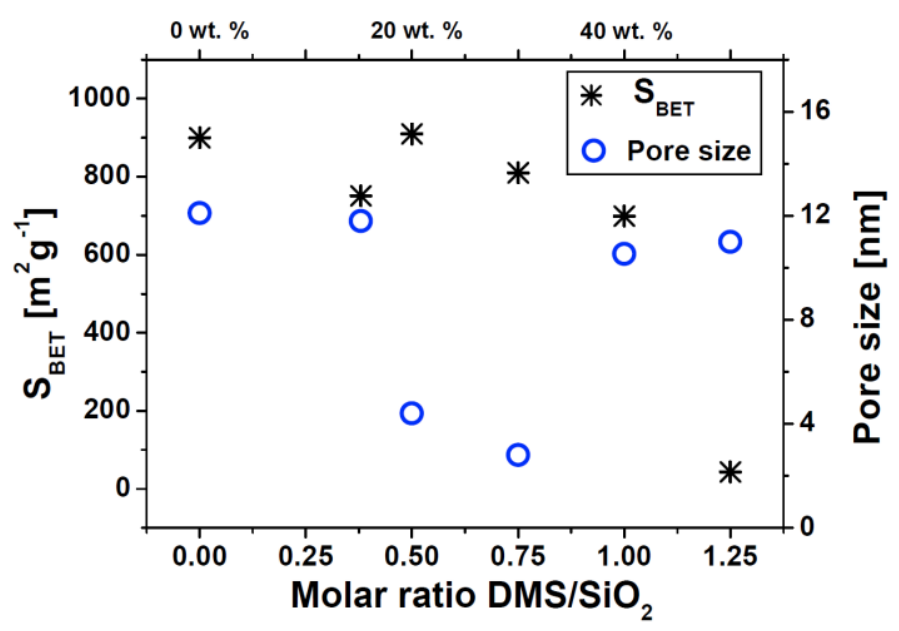

Fig. 2 Specific surface area and pore size of the samples with different organic content, obtained from nitrogen physisorption experiments

The specific surface area drops from typical pure inorganic silica aerogel values, that is, from $\sim 900 \mathrm{~m}^{2} \mathrm{~g}^{-1}$ to $43 \mathrm{~m}^{2} \mathrm{~g}^{-1}$ (Fig. 2). The progressive inclusion of the organic phase within the porous volume of the silica porous matrix (increasing the organic content from TD0.38 to TD1.00) causes a significant reduction of the porous volume and pore size. And finally, the final decrease of the specific surface area of sample TD1.25 reveals that the character of the sample has changed, as explained before, from an inorganic silica aerogel matrix to an organic porous matrix with bigger structural elements [iError! Marcador no definido.]. This behaviour is roughly similar to that of the specific porous volume (Table 1). The average pore size and S/V ratio also showed a clear transition between the inorganic and highly organic sample (TD1.25), revealing the organic content crossover between 0.5 - 1.00 DEDMS:TEOS molar ratio. In Fig. SM2 (Online Resource 1), the dependence of the density and specific porous volume on the organic content is plotted, and a similar behaviour can also be seen.

Scanning electron microscopy micrographs showed the different morphology of the two samples with extreme values of organic content, namely, TD0 and TD1.25, at the micrometer level (Fig. 3). At the selected magnification, both samples presented the typical coarse texture of the hierarchically ordered porous matrixes of the silica aerogels that can be observed at this length scales [30,31], but some differences clearly aroused. It can be easily seen that the inorganic matrix TD0 presents a finer texture, with structural features of less than $1 \mu \mathrm{m}$. On the contrary, the hybrid matrix of the TD1.25 sample presents a broader porous matrix apparent at this scale, with abundant large pores $(\geq 0.1 \mu \mathrm{m})$, with an associated macropore size distribution. 


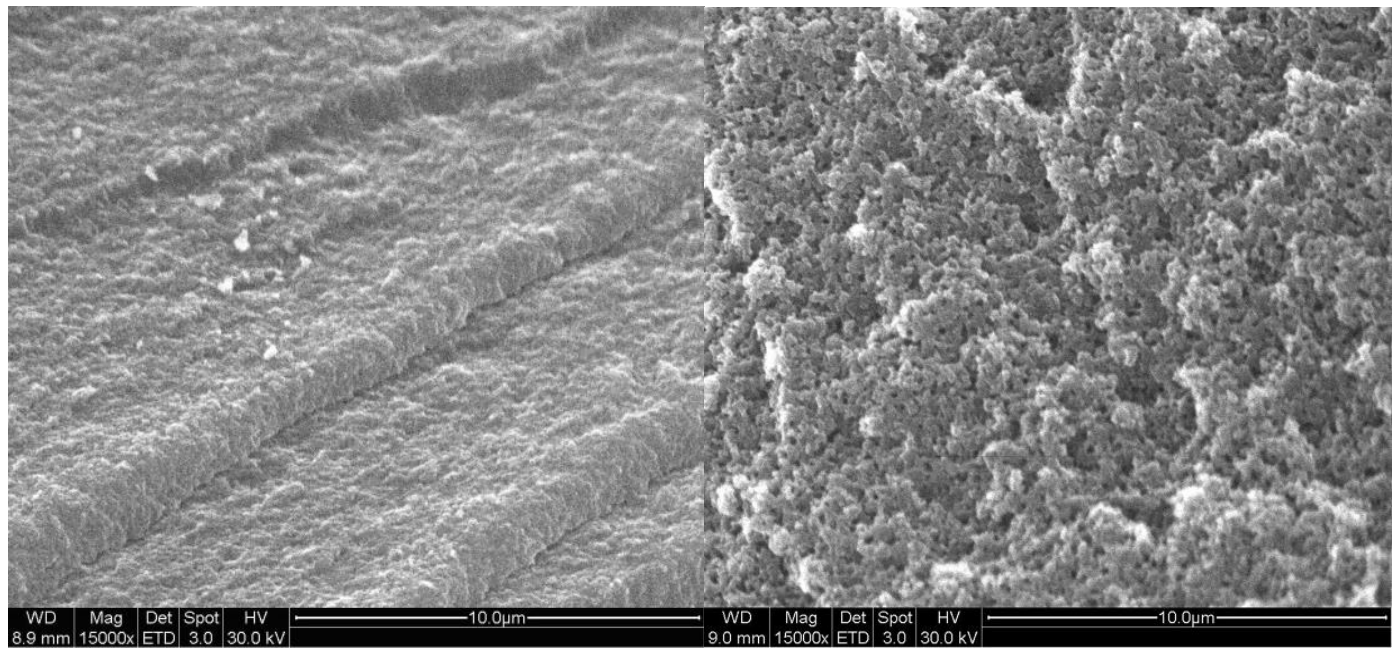

Fig. 3 Scanning electron micrographs of pure silica sample TD0 (left), and hybrid sample TD1.25 (right). Different particulate features are apparent.

\subsection{Absorption experiments}

\subsubsection{Absorption capacity}

The ability of these samples to absorb different organic fluids was tested, and the results of the total absorbed mass ratio are shown in Table 2. As a general rule, the sample TD0 absorbs more fluid in relative terms than the hybrid TD1.25, but the rigidity of the sample skeleton TD0 of pure silica led to the appearance of cracks. This fact highlights the relevance of the mechanical performance upon absorption for the development of technologies based on these samples. These features are studied in the sections below.

\begin{tabular}{|c|c|c|c|c|c|c|c|c|c|}
\hline \multirow{2}{*}{$\begin{array}{c}\text { Absorption } \\
\text { capacity } \\
\left(\% \text { use of } V_{p}\right)\end{array}$} & \multicolumn{9}{|c|}{$\begin{array}{c}\text { Absorbate } \\
\left(\text { density, } \mathrm{g} \mathrm{cm}^{-3}\right)\end{array}$} \\
\hline & $\begin{array}{c}\text { Hexane } \\
(0.695)\end{array}$ & $\underset{(0.684)}{\text { Heptane }}$ & $\begin{array}{c}\text { Octane } \\
(0.703)\end{array}$ & $\begin{array}{c}\text { Tetra- } \\
\text { hydrofurane } \\
(0.883)\end{array}$ & $\begin{array}{c}\text { Toluene } \\
(0.867)\end{array}$ & $\begin{array}{c}\text { Benzene } \\
(0.876)\end{array}$ & $\begin{array}{c}\text { Ethanol } \\
(0.789)\end{array}$ & $\begin{array}{c}\text { Motor } \\
\text { oil } \\
(0.875) \\
\end{array}$ & $\begin{array}{c}\underset{(0.965)}{\text { PDMS }} \\
\text { D. }\end{array}$ \\
\hline TD0 & $\begin{array}{l}1.55 \\
(67) \\
\end{array}$ & $\begin{array}{l}1.77 \\
(78) \\
\end{array}$ & $\begin{array}{l}2.07 \\
(89) \\
\end{array}$ & $\begin{array}{c}2.66 \\
(91) \\
\end{array}$ & $\begin{array}{c}2.23 \\
(78) \\
\end{array}$ & - & $\begin{array}{c}2.54 \\
(97) \\
\end{array}$ & $\begin{array}{c}2.40 \\
(83) \\
\end{array}$ & $\begin{array}{l}2.75 \\
(86) \\
\end{array}$ \\
\hline TD1.25 & $\begin{array}{c}0.94 \\
(1040)\end{array}$ & $\begin{array}{l}1.07 \\
(1203)\end{array}$ & $\begin{array}{c}1.70 \\
(1860)\end{array}$ & $\begin{array}{l}1.61 \\
(1403)\end{array}$ & $\begin{array}{c}1.57 \\
(1393)\end{array}$ & $\begin{array}{c}1.57 \\
(1379)\end{array}$ & $\begin{array}{c}1.57 \\
(1531)\end{array}$ & $\begin{array}{c}1.89 \\
(1662)\end{array}$ & $\begin{array}{c}1.83 \\
(1459)\end{array}$ \\
\hline
\end{tabular}

Table 2 Absorption capacity values for TD0 and TD1.25 samples in terms of the ratio of absorbed mass of the organic liquid per unit mass of the dry sample. The use of the porous volume was assessed by comparing the theoretical volume occupied by the absorbed organic fluid $\left(\mathrm{V}_{\mathrm{abs}}\right)$ with the porous volume of the dry sample $\left(\mathrm{V}_{\mathrm{p}}\right)$. 
The response of both porous structures can be compared from a geometric point of view. Considering $1 \mathrm{~g}$ of absorbent sample, the TD0 has $3.306 \mathrm{~cm}^{3}$ of porous volume available to be occupied by the absorbent, whereas sample TD1.25 has only $0.130 \mathrm{~cm}^{3}$. In the case that these porous volumes become fully filled with liquid PDMS (0.965 $\mathrm{cm}^{3} / \mathrm{g}$ ) (considering that the matrix remains immutable upon absorption), the consequent increase of the mass will give absorbed mass ratios of 3.19 and 0.13 for TD0 and TD1.25, respectively. Instead, the experimental absorbed mass ratios are 2.75 and 1.83 (see Table 2). These results prove that the porous volume of the inorganic sample TD0 is not fully filled with oily fluid, considering the simplest model of an unmodified porous structure. On the contrary, sample TD1.25 confirmed that the absorbed volume of PDMS was more than 13 times the porous volume for a variety of organic solvents and oily fluids (motor oil and liquid PDMS). Size measurements after absorption experiments confirmed volume variations of the TD0 sample below $4 \%$, indicating that TD0 absorbs solvent by simple imbibition. In the case of sample TD1.25, the increase of volume of the sample reached up to $15 \%$ (without breakage) thanks to the swelling response of the organic chains of the matrix. The occurrence of swelling when a polymer is added to a given solvent is due to attraction as well as dispersion forces which begin acting between polymer segments, according to their polarity, chemical characteristics, and solubility parameter. If the polymer-solvent interactions are higher than the polymer-polymer attraction forces, the chain segments start to absorb solvent molecules, increasing the volume of the polymer matrix, and loosening out from their coiled shape. It can be stated that the hybrid organic/inorganic porous skeleton of sample TD1.25 experiences swelling when soaked in organic solvents and oily liquids.

\subsubsection{Absorption kinetics}

The absorption behaviour was described by the normalized absorption ratio $M^{*}(t)$

(Fig. 4). The plot of two representative curves of the normalized mass $M^{*}$ versus $t^{0.5}$ for samples TD0 and TD1.25 clearly reveals well-defined initial linear regimes, according to the classical time-dependence $[1,32,33]$, followed by final regimes departing from the linear behaviour up to saturation. 


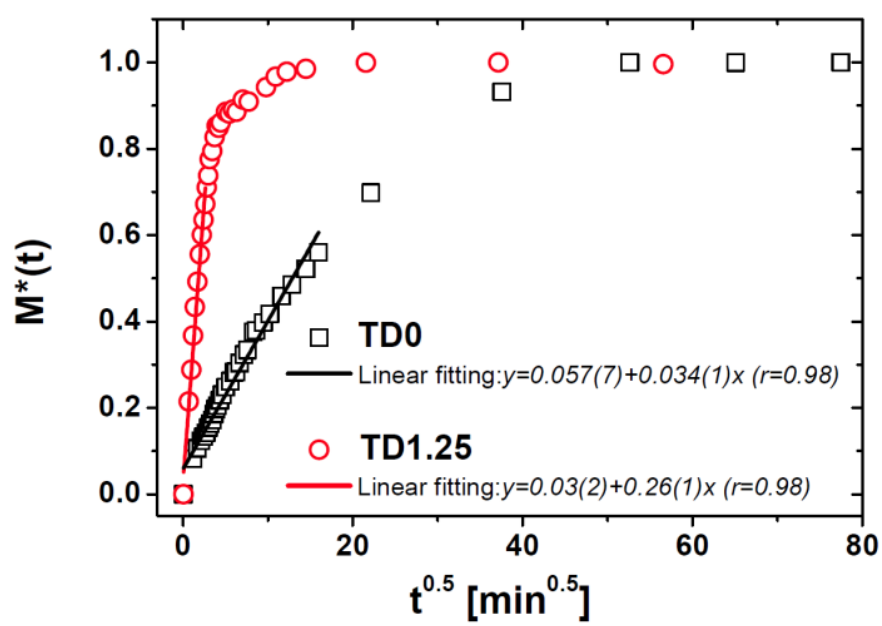

Fig. 4 Normalized absorbed mass ratio for TD0 and TD1.25 aerogels during liquid PDMS intake versus square-root time. Lines correspond to linear fittings according to standard model of mass increase due to capillary rise

Typically, the variation of the sample mass of porous media due to the imbibition of liquids by capillary rise, considering a rigid porous structure, shows a time-dependence as $M(t) \sim t^{0.5}$. Our experimental results indicated that both samples fit well the linear trend before reaching saturation. But the faster (steeper) linear regime of the hybrid sample reveals the different nanostructure and chemical composition of the porous network. The affinity of the organic chains of the porous matrix to the liquid PDMS, together with the non-negligible swelling phenomenon observed in the hybrid structure, would be responsible for the enhancement of the absorption kinetics (by almost one order of magnitude, regarding the slope of the linear fitting). But these first studies of the kinetic dependence of the absorption with the organic content of hybrid aerogels show that further thorough research is necessary in order to accurately resolve the complex absorption kinetics of these samples and to allow the absorption kinetics to be controlled by tuning the relative organic/inorganic composition. Some snapshots of different moments of the absorption process of liquid PDMS in sample TD1.25 are shown in Fig. SM3 in Online Resource 1.

\subsubsection{Structure of the wet samples}

The SEM images showed the morphology of the fracture found on the surface of the wet aerogels, TD0w and TD1.25w (Fig. 5). The wet TD0 and the swollen TD1.25 samples revealed a singular transformation of the microstructure, suggesting significant morphological changes in the porous matrix due to the incorporation of organic phase. 
The pure silica wet sample TD0w presented a coarse structure very different to the original structure (Fig. 3, left; note that the pictures were taken at the same scale for the sake of comparison) and very close to the TD1.25 (Fig. 3, right).

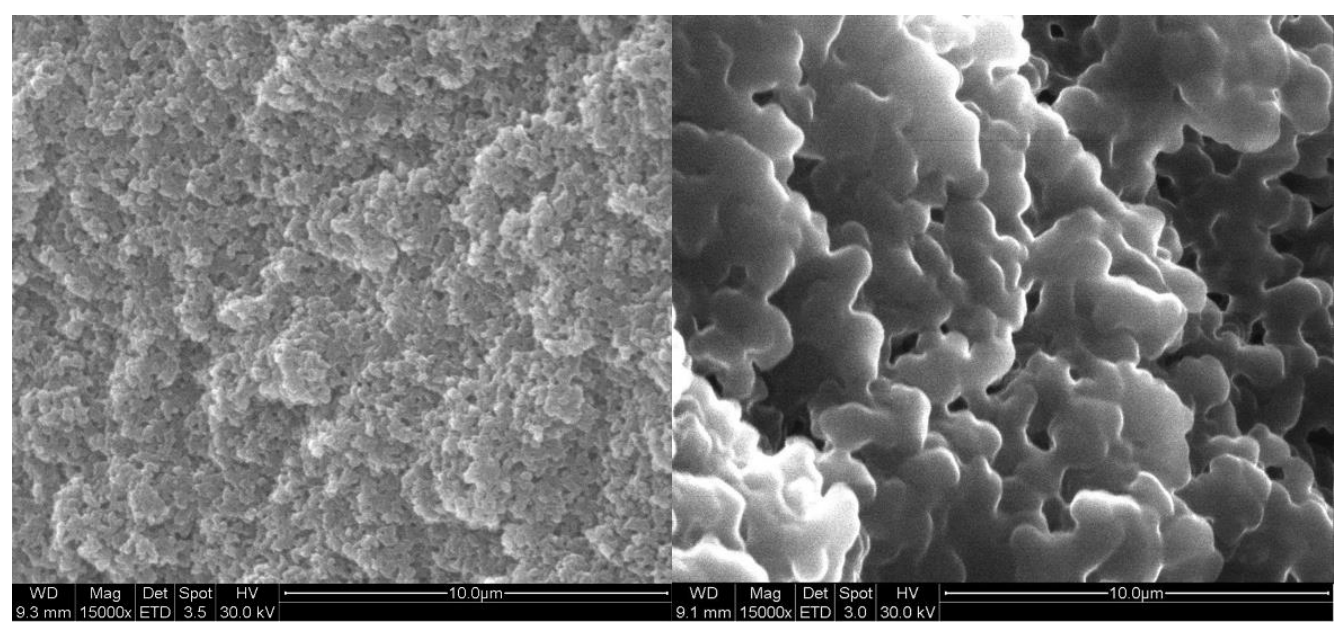

Fig. 5 SEM micrographs of TD0w (left) and TD1.25w aerogels after soaking in liquid PDMS

On the other hand, the microstructure of the TD1.25w has lost the coarse texture observed prior to oil absorption, indicating the loss of sub-microstructure. Large swollen structures formed by aggregates of rounded particles of about 1 micron size are observed, which in turn retained the cross-link 3D network from the original dry hybrid aerogel. These particles are filled by PDMS chains with strong affinity to the DMS molecular chains formed in situ. Also, it should be noticed that the vacuum of the SEM chamber did not remove by evaporation the PDMS from the samples and the wet samples appear very different to their dry counterparts, indicating the strong affinity between the absorbed PDMS and the matrix of the samples.

The FTIR analyses gave more clues about the structure of the wet samples (Fig. 6). First of all, there is a significant change between the TD0 and TD0w spectra: the absence of the both $3454 \mathrm{~cm}^{-1}$ and $969 \mathrm{~cm}^{-1}$ absorption peaks in the wet sample is due to the presence of liquid PDMS, which is absorbed on the surface. On the other hand, the spectra of the DMS-bearing samples, namely, TD0w, TD1.25 and TD1.25w, are very similar because they all contain basically the same functional groups, being indistinguishable from the point of view of the IR functional compound analysis. Nevertheless, a small peak at $895 \mathrm{~cm}^{-1}$ is only observed in sample TD1.25w, which is characteristic of the resting precursor DMDES [34]. 


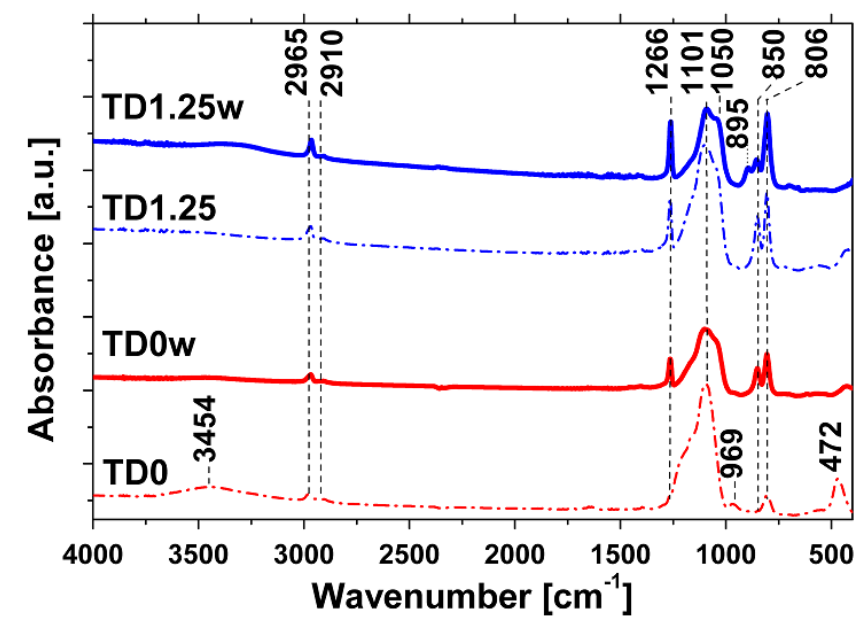

Fig. 6 FTIR Fourier-transformed infrared spectra of TD0w and TD1.25w. FTIR from original samples TD0 and TD1.25 are plotted for comparison purposes

\subsection{Mechanical properties}

The analyses of the mechanical properties were performed on the samples before and after the liquid absorption experiments. In Fig. 7, comparisons of the stress-strain curves of different uniaxial compression experiments on sample TD0 (left panel) and sample TD1.25 (right panel) are plotted: rupture test and load-unload cycle at $80 \%$ of strain-at-failure for dry and wet saturated with common motor oil and liquid PDMS. Thus, the mechanical response of the porous structures of the samples can be compared between dry and immersed in two different oily liquids.
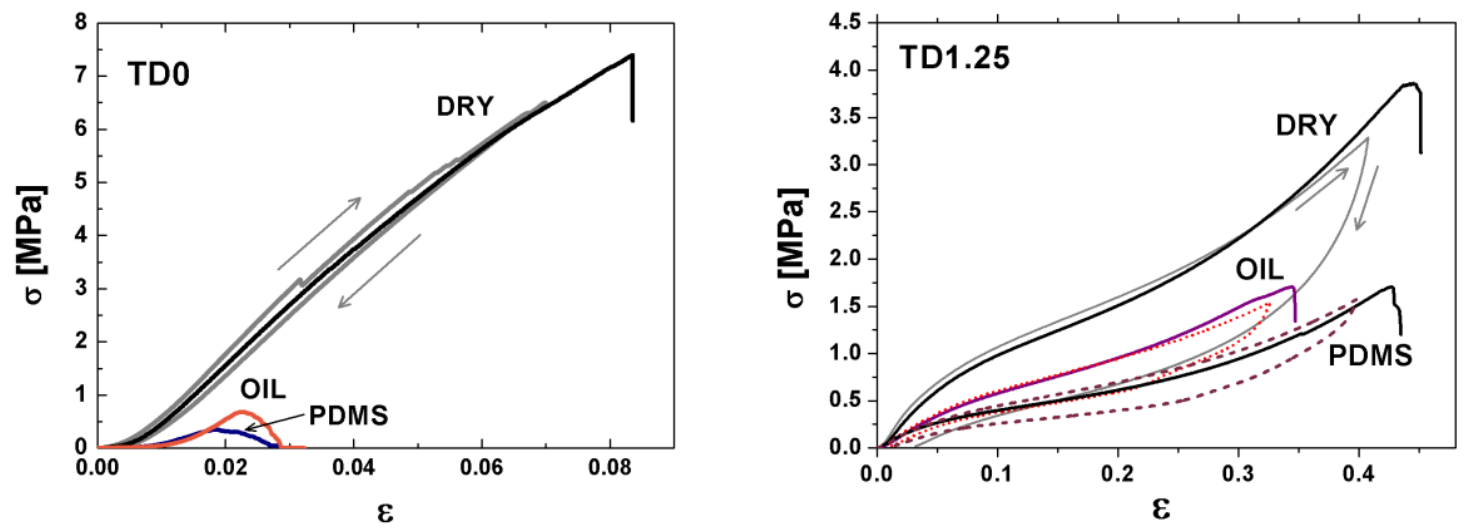

Fig. 7 Stress-strain curves of rupture tests and load-unload cycle at $80 \%$ of strain-atfailure upon uniaxial compression, for dry and wet samples immersed in the indicated liquids (where "oil" refers to common motor oil) of samples TD0 (left) and TD1.25 (right). Inset shows compression set behaviour of dry sample TD1.25 after $25 \%$ strain 
The uniaxial compression experiments gave a general view of the mechanical character of the samples, and informed about the Young's modulus, stress-at-failure and rupture strain. In Fig. SM4 in Online Resource 1, two pictures of the uniaxial compression experiments can be seen. The dry TD0 behaved as a typical pure silica aerogel, that is, as a brittle sample, and without a hysteresis loop upon the load-unload test, with a Young's modulus of $88.9 \mathrm{MPa}, 7.4 \mathrm{MPa}$ of stress-at-failure, and $10 \%$ maximum strain (Table 3). On the contrary, the dry TD1.25 sample showed an elastomeric behaviour with a clear hysteresis loop, characteristic of hybrid materials with organic phases. The different regions that can be observed reveal the complex interplay of the constituent phases. The averaged Young's modulus and stress-at-failure were found to be 7.8 $\mathrm{MPa}$ and 3.8 $\mathrm{MPa}$, much lower than the values obtained for sample TD0. But a large increase of the maximum strain (more than 4-fold) was achieved in sample TD1.25. All these changes are in accordance with the general behaviour previously reported for similar samples [11, 12, 35-37]. Therefore, the incorporation of the 1.25 molar ratio of DMS into the inorganic silica matrix facilitated the handing of the sample.

\begin{tabular}{|c|ccc|ccc|ccc|ccc|}
\hline \multicolumn{1}{c}{} & \multicolumn{3}{c}{$\begin{array}{c}\text { Young's modulus } \\
\text { (MPa) }\end{array}$} & \multicolumn{3}{c}{$\begin{array}{c}\text { Stress-at-failure } \\
\text { (MPa) }\end{array}$} & \multicolumn{2}{c}{ Rupture strain } & \multicolumn{3}{c|}{$\begin{array}{c}\text { Energy loss } \\
\left(\text { mJ g }^{-1}\right)\end{array}$} \\
\cline { 2 - 14 } & Dry & Oil & PDMS & Dry & Oil & PDMS & Dry & Oil & PDMS & Dry & Oil & PDMS \\
\hline TD0 & 88.9 & - & - & 7.4 & 0.7 & 0.4 & 0.10 & 0.02 & 0.02 & 45 & - & - \\
\hline TD1.25 & 7.8 & 4.4 & 3.2 & 3.8 & 1.6 & 1.6 & 0.44 & 0.34 & 0.43 & 920 & 237 & 276 \\
\hline
\end{tabular}

Table 3 Mechanical properties of the dry samples and wet samples after saturation by the absorption of two different liquids, motor oil and liquid PDMS. Extremely low stress-at-failure for sample TD0 loaded by motor oil and PDMS made meaningless the estimations of Young's moduli or energy losses.

On the other hand, the uniaxial compression experiments of the wet inorganic sample TD0w led to immediate failure, as the mere absorption process produced visible cracks on the samples. Thus, rupture strains of sample TD0w were found at $\varepsilon=0.02$ for both liquids. Thereby, the Young's moduli in TD0w were neglected as the sample failed very quickly. On the contrary, in the case of the wet hybrid sample TD1.25w, uniaxial compression experiments led to expel the absorbed liquid, and the observed behaviour showed a stress-at-failure of $1.6 \mathrm{MPa}$ at maximum strains of $\varepsilon=0.36$ and $\varepsilon=0.43$ with motor oil and PDMS, respectively. Besides, the hybrid structure was found to be more compliant when filled by liquid PDMS, but in both cases, a wide range of mechanical 
deformation was obtained. Young's moduli of 4.4 MPa and 3.2 $\mathrm{MPa}$ were estimated with oil and PDMS, respectively. An in depth mechanical characterization of this kind of samples before and after absorption of different liquids could be considered, together with the previous research in bioactive composite materials based on mineral-organicsilica aerogels [38-41], in order to establish first steps for developing new exploitable features for biomaterial applications.

Regarding the reusability and the solvent recovery upon uniaxial compression, a first approach has been made by load-unload cycles and the expelled absorbed liquid has been measured. The samples were tested in three consecutive cycles at $45 \%$ of maximum load (Fig. SM5 in Online Resource 1) in which $25 \%$ of the volume of the liquid has been recovered without any significant change in the mechanical response. This low value of recovered liquid is the subject of current research.

Finally, the elastomeric character of the hybrid sample TD1.25 was also characterized by the compression set (inset in Fig. 7, right) and by the area of the hysteresis loops of the load-unload experiments. The hybrid sample showed an almost complete recuperation of the original size after load release for $5 \mathrm{~h}$, with a remaining compression set below 0.03. The area of the hysteresis loops observed in the stressstrain curve gave clues about the difference between the energy stored in the material during loading and the energy recovered during unloading. Thus, this enclosed region is a measure of the energy lost as heat transfer mechanisms during the deformation, and also a typical signal of the viscoelastic behaviour. The corresponding energy loss values calculated for the cycle test from the TD0 and TD1.25 samples are included in Table 3. TD0 resulted in a very low energy loss $\left(45 \mathrm{~mJ} \mathrm{~g}^{-1}\right)$, as corresponds to an almost purely elastic material. However, that energy increases by almost 20 times for sample TD1.25, indicating a drastic variation of the mechanical behaviour due to the presence of DEDMS, which allows significant energy dissipation by the response of the network of crosslinked organic chains. Wet sample TD1.25w showed intermediate energy losses, depending on the type of fluid: $237 \mathrm{~mJ} \mathrm{~g}^{-1}$ corresponds to the viscoelastic response of TD1.25w completely saturated by PDMS and $276 \mathrm{~mJ} \mathrm{~g}^{-1}$ in the case of motor oil. Visibly, the absorption of the oily solvent within the network of sample TD1.25w yields a less dissipative organic network. Finally, the small differences between motor oil and PDMS arose from the different viscosities of the two types of liquids. 


\section{Conclusions}

The increasing inclusion of organic phase in the silica-based aerogels changes the sample character from brittle to elastomeric, with a critical concentration ca. $50 \%$ molar ratio. These results confirmed the expected behaviour for hybrid aerogels. Thus, with increasing organic content, the specific surface area decreased from $\sim 900 \mathrm{~m}^{2} \mathrm{~g}^{-1}$ to $43 \mathrm{~m}^{2} \mathrm{~g}^{-1}$, or comparing extreme organic concentrations, the Young's modulus was reduced from $88.9 \mathrm{MPa}$ to $7.9 \mathrm{MPa}$, and the rupture strain increased more than four times, up to 0.44 . From another point of view, the structure and mechanical properties of these samples can be tuned by controlling the organic content. In addition, the absorption ratios of the samples achieved up to 2.75 for dry samples but they do not fill completely the available porous volume. Moreover, the inorganic samples became very fragile when wet, that is, when loaded with solvent, and they broke in most cases. On the contrary, the inclusion of the organic phase reduced the absorption capacity of the samples, but conferred large deformability by uniaxial compression on the wet aerogels, allowing partial solvent recovery and their reusability. Besides, the absorption kinetics was enhanced enormously. It was also verified that hybrid samples absorb much more solvent than expected by their porous volume thanks to the absorption by swelling. Thereby, the relative organic content is confirmed as a versatile property for controlling the absorption features of these samples.

Acknowledegements V.M-F. thanks the post-doctoral grant from the "V Plan Propio de Investigación" from the University of Seville. In addition, contributions and help supplied by the ImageJ software package developers, from the National Institutes of Health of the US (http://imagej.nih.gov/ij), and from the webmasters and owners of www.citethisforme.com have also to be recognized. Technical staff of the CITIUS (Universidad de Sevilla) is also acknowledged for their help in the characterization of the samples and the funding from the "Proyecto de Excelencia, P09-TEP-5463" of the Consejería de Economía, Innovación, Ciencia y Empleo, Junta de Andalucía is acknowledged as well.

\section{References}


1 Alava M, Dubé M, Rost M (2004) Imbibition in disordered media. Advances in Physics 53:83-175. DOI: $10.1080 / 00018730410001687363$

2 Bear J (1988) Dynamics of fluids in porous media. Dover publications INC., New York

3 Adebajo M, Frost R, Kloprogge J, Carmody O, Kokot S (2003) Porous materials for oil spill cleanup: A review of synthesis and absorbing properties. Journal of Porous Materials 10:159-170. DOI: 10.1023/a:1027484117065

4 Omidian H, Hashemi S, Sammes P, Meldrum I (1998) A model for the swelling of superabsorbent polymers. Polymer 39:6697-6704. DOI: 10.1016/s0032-3861(98)00095-0

5 Fratzl P, Barth F (2009) Biomaterial systems for mechanosensing and actuation. Nature 462:442-448. DOI: 10.1038 /nature08603

6 Burgert I, Fratzl P (2009) Actuation systems in plants as prototypes for bioinspired devices. Philosophical Transactions of the Royal Society A: Mathematical, Physical and Engineering Sciences 367:1541-1557. DOI: 10.1098/rsta.2009.0003

7 Anderson AM, Carroll MK (2011) In: Aegerter MA, Leventis N, Koebel MM (eds.), Aerogels Handbook, Advances in Sol-Gel Derived Materials and Technologies, Springer-Verlag New York. DOI: 10.1007/978-1-4419-7589-8_4

8 Standeker S, Novak Z, Knez Ž (2007) Adsorption of toxic organic compounds from water with hydrophobic silica aerogels. Journal of Colloid and Interface Science 310:362-368. DOI: 10.1016/j.jcis.2007.02.021

9 Anderson A, Carroll M, Green E, Melville J, Bono M (2010) Hydrophobic silica aerogels prepared via rapid supercritical extraction. J Sol-Gel Sci Technol 53:199-207. DOI: 10.1007/s10971-009-2078-Z

10 Martín L, Ossó J, Ricart S, Roig A, García O, Sastre R (2008) Organo-modified silica aerogels and implications for material hydrophobicity and mechanical properties. J Mater Chem 18:207-213. DOI: $10.1039 / \mathrm{b} 712553 \mathrm{~d}$

11 Mackenzie JD, Bescher E (1998) Structures, properties and potential applications of Ormosils. J.Solgel Sci. Tech. 13:371-377

12 De la Rosa-Fox N, Morales-Flórez V, Toledo-Fernández JA, Piñero M, Mendoza-Serna R, Esquivias, L (2007) Nanoindentation on hybrid organic-inorganic silica aerogels. J. Eur. Ceram. Soc. 11:3311-3316. DOI: $10.1016 /$ jeurceramsoc.2007.02.09

13 Randall J, Meador M, Jana S (2011) Tailoring Mechanical Properties of Aerogels for Aerospace Applications. ACS Appl Mater Interfaces 3:613-626. DOI: 10.1021/am200007n

14 Morales-Flórez V, Rosa-Fox N, Piñero M, Esquivias L (2005) The Cluster Model: A Simulation of the Aerogel Structure as a Hierarchically-Ordered Arrangement of Randomly Packed Spheres. J Sol-Gel Sci Technol 35:203-210. DOI: 10.1007/s10971-005-2363-4

15 Pierre A, Rigacci A (2011) In: Aegerter MA, Leventis N, Koebel MM (eds.), Aerogels Handbook, Advances in Sol-Gel Derived Materials and Technologies, Springer-Verlag New York. DOI: 10.1007/978-1-4419-7589-8_4

16 Choi S, Kwon T, Im H, Moon D, Baek D, Seol M, Duarte J, Choi Y (2011) A Polydimethylsiloxane (PDMS) Sponge for the Selective Absorption of Oil from Water. ACS Appl Mater Interfaces 3:45524556. DOI: $10.1021 / \mathrm{am} 201352 \mathrm{w}$ 
17 Zhao X, Li L, Li B, Zhang J, Wang A (2014) Durable superhydrophobic/superoleophilic PDMS sponges and their applications in selective oil absorption and in plugging oil leakages. J Mater Chem A 2:18281-18287. DOI: 10.1039/c4ta04406a

18 Yoo S, Cohen C, Hui C (2006) Mechanical and swelling properties of PDMS interpenetrating polymer networks. Polymer 47:6226-6235. DOI: 10.1016/j.polymer.2006.06.035

19 Haraguchi K, Takehisha T (2002) Nanocomposite hydrogels; a unique organic-inorganic network structure with extraordinary mechanical, optical, and swelling/de-swelling properties. Adv. Mater. $14: 1120-1124$

20. Rosa-Fox N, Morales-Flórez V, Toledo-Fernández J, Piñero M, Esquivias L, Keiderling U (2008) SANS study of hybrid silica aerogels under "in situ" uniaxial compression. J Sol-Gel Sci Technol 45:245250. DOI: $10.1007 / \mathrm{s} 10971-008-1686-3$

21 Babonneau F, Bois L, Maquet J, Livage J (1992) In: Vilminot S, Nass R, Schmidt H (eds.), Eurogel'91 - Progress in Research and Development of Processes and Products from Sols and Gels. Elsevier Science Publishers, Amsterdam

22 Babonneau F (1994) Hybrid siloxane-oxide materials via sol-gel processing: Structural characterization. Polyhedron 13:1123-1130. DOI: 10.1016/s0277-5387(00)80249-1

23 Gedde U, Hellebuych A, Hedenqvist M (1996) Sorption of low molar mass silicones in silicone elastomers. Polym Eng Sci 36:2077-2082. DOI: 10.1002/pen.10603

24 Morales-Flórez V, Toledo-Fernandez JA, De la Rosa-Fox N, Piñero M, Esquivias L (2008) Percolation of the organic phase in hybrid organic-inorganic aerogels. J Sol-Gel Sci Technol 50:170-175. DOI: $10.1007 / \mathrm{s} 10971-008-1874-1$

25 Zhuravlev LT (2000) The surface chemistry of amorphous silica. Zhuravlev model. Colloids and Surfaces A: Physicochemical and Engineering Aspects 173: 1-38. DOI: 10.1016/S0927-7757(00)00556-2

26 Portaccio M, Della Ventura B, Mita D, Manolova N, Stoilova O, Rashkov I, Lepore M (2011) FT-IR microscopy characterization of sol-gel layers prior and after glucose oxidase immobilization for biosensing applications. J Sol-Gel Sci Technol 57:204-211. DOI: 10.1007/s10971-010-2343-1

27 Al-Oweini R, El-Rassy H (2009) Synthesis and characterization by FTIR spectroscopy of silica aerogels prepared using several $\mathrm{Si}(\mathrm{OR})_{4}$ and $\mathrm{R}^{\prime \prime} \mathrm{Si}\left(\mathrm{OR}^{\prime}\right)_{3}$ precursors. Journal of Molecular Structure 919:140-145. DOI: 10.1016/j.molstruc.2008.08.025

$28 \mathrm{Wu}$ W, Chuang C, Lin J (2000) Bonding Geometry and Reactivity of Methoxy and Ethoxy Groups Adsorbed on Powdered $\mathrm{TiO}_{2}$. The Journal of Physical Chemistry B 104:8719-8724. DOI: $10.1021 /$ jp0017184

29 Kruk M, Jaroniec M (2001) Gas Adsorption Characterization of Ordered Organic-Inorganic Nanocomposite Materials. Chemistry of Materials 13:3169-3183. DOI: 10.1021/cm0101069

30 Morales-Flórez V, Piñero M, de la Rosa-Fox N, Esquivias L, Anta J, Primera J (2008) The cluster model: A hierarchically-ordered assemblage of random-packing spheres for modelling microstructure of porous materials. Journal of Non-Crystalline Solids 354:193-198. DOI: 10.1016/j.jnoncrysol.2007.07.061

31 Morales-Flórez V, Rosa-Fox N, Piñero M, Esquivias L (2005) The Cluster Model: A Simulation of the Aerogel Structure as a Hierarchically-Ordered Arrangement of Randomly Packed Spheres. J Sol-Gel Sci Technol 35:203-210. DOI: 10.1007/s10971-005-2363-4 
32 Gruener S, Hermes H, Schillinger B, Egelhaaf S, Huber P (2015) Capillary rise dynamics of liquid hydrocarbons in mesoporous silica as explored by gravimetry, optical and neutron imaging: Nanorheology and determination of pore size distributions from the shape of imbibition fronts. Colloids and Surfaces A: Physicochemical and Engineering Aspects. DOI: 10.1016/j.colsurfa.2015.09.055

33 Mosquera M, Rivas T, Prieto B, Silva B (2000) Capillary Rise in Granitic Rocks: Interpretation of Kinetics on the Basis of Pore Structure. Journal of Colloid and Interface Science 222:41-45. DOI: 10.1006/jcis.1999.6612

34 Zhang Z, Gorman BP, Dong H, Orozco-Teran RA, Mueller DW, Reidy RF (2003) Investigation of Polymerization and Cyclization of Dimethyldiethoxysilane by ${ }^{29} \mathrm{Si}$ NMR and FTIR. J Sol-Gel Sci Technol 28:159-165. DOI: 10.1023/A:1026098729993

35 Leventis N, Lu H (2011) In: Aegerter MA, Leventis N, Koebel MM (eds.), Aerogels Handbook, Advances in Sol-Gel Derived Materials and Technologies, Springer-Verlag New York. DOI: 10.1007/978-1-4419-7589-8_4

36 Piñero M, Morales-Florez V, De la Rosa-Fox N, Esquivias L (2005) Propiedades mecánicas de aerogeles híbridos de sílice. Boletín de la Sociedad Española de Cerámica y Vidrio 44:291-203.

37 De la Rosa-Fox N, Toledo-Fernández JA, Morales-Florez V, Piñero M, Esquivias L (2010) Creep and stress relaxation of hybrid organic-inorganic aerogels. Key Engineering Materials 423:167-172. DOI:10.4028/www.scientific.net/KEM.423.167

38 Kamitakahara M, Kawashita M, Miyata N, Kokubo T, Nakamura T (2001) Bioactivity and mechanical properties of polydimethylsiloxane (PDMS)-CaO-SiO 2 hybrids with different PDMS contents. Journal of Sol-Gel Science and Technology 21:75-81. DOI: 10.1023/a:1011261617377

39 Esquivias L, Morales-Flórez V, Piñero M, de la Rosa-Fox N (2005) Structure of bioactive mixed polymer/colloid aerogels. Journal of Non-Crystalline Solids 351:3347-3355. DOI: 10.1016/j.jnoncrysol.2005.08.007

40 Toledo-Fernández J, Mendoza-Serna R, Morales V, de la Rosa-Fox N, Piñero M, Santos A, Esquivias L (2007) Bioactivity of wollastonite/aerogels composites obtained from a TEOS-MTES matrix. J Mater Sci: Mater Med 19:2207-2213. DOI: 10.1007/s10856-007-3312-2

41 Toledo Fernández J, Mendoza-Serna R, Santos A, Piñero M, Rosa-Fox N, Esquivias L (2008) Improvement of the bioactivity of organic-inorganic hybrid aerogels/wollastonite composites with $\mathrm{TiO}_{2}$. J Sol-Gel Sci Technol 45:261-267. DOI: 10.1007/s10971-007-1674-Z 